\title{
Konteks Sosial-Politik Desain Green Campus Universitas Riau ${ }^{1}$
}

\author{
Khairul Anwar² dan Syamsul Bahri \\ Pengajar Ilmu Politik, Jurusan Ilmu Pemerintahan, Fakultas Ilmu Sosial dan \\ Politik, Universitas Riau
}

\begin{abstract}
Abstrak Penelitian ini bertujuan mendeskripsikan respon civitas kampus terhadap implementasi kebijakan desain Kampus Hijau Universitas Riau berbasis budaya Melayu. Metode yang digunakan dalam mencapai tujuan itu adalah dengan cara mengidentifikasi (1) Siapa saja aktor atau kelompok dan kepentingannya? (2) Apa saja regulasi yang terkait pengelolaan kampus hijau; dan, (3) apa sarana dan prasarana pendukung yang ada? Penelitian menunjukkan bahwa: Pertama, ada pro kontra terhadap implementasi konsep green campus berbasis budaya Melayu. Aktor yang kontra mempersepsikan pembangunan green campus lebih berorientasi skema kerja yang bersifat pisik. Kedua, aktor yang pro terhadap riset green campus melihat kerja riset selaras dengan konsep pembangunan yang berkelanjutan dan selaras nilai budaya Melayu. Ada tiga aspirasi yang berkembang yaitu keamanan dan kebersihan kampus hijau, efisiensi dalam pengelolaan, dan sarana prasarana pendukung. Oleh karena itu, dalam rangka mengimplementasikan konsep green campus dapat diarahkan kepada tiga kegiatan yaitu: green transportation; green energy; dan green building.
\end{abstract}

Kata kunci: Kelembagaan, green campus, lingkungan sosial-politik.

Abstract This study aimed to describe the response of the campus community to design policy implementation based Green Campus, University of Riau Malay culture. The method used to achieve that goal is to identify; (1) Who are the actors or groups and interests?; (2) Any regulations in relation to the management of the green campus and, (3) what existing infrastructure?. Research shows that: First, there are pros and cons of the concept of culture-based green campus counter melayu.Actor perceive green campus-oriented development schemes of work that is pisik.Second, actor Pro to research green campus see the research work in harmony with the concept of sustainable development, There are three growing aspirations of a green campus safety and cleanliness, efficiency in the management and supporting infrastructure. Therefore, in order to implementation green campus can be directed to three activities, namely: green transportation; green energy and green building.

\footnotetext{
${ }^{1}$ Sebagian besar data pada artikel ini adalah hasil riset Tim Desain Pengelolaan Kampus Hijau Berbasis Konservasi dan Budaya Melayu. Penulis anggota tim dengan fokus kajian Dimensi Sosial-Budaya Kampus Hijau. Penelitian ini dibiayai oleh Lembaga Penelitian dan Pengabdian Kepada Masyarakat (LPPM) Universitas Riau tahun 2016 melalui Pusat Studi Lingkungan Hidup (PSLH) Universitas Riau.

${ }^{2}$ E-mail penulis koresponden: khairulanwar147@yahoo.com
} 
Keywords: Institutional, green campus, socio-political environment

\section{PENDAHULUAN}

Secara politik, implementasi kebijakan mewujudkan Universitas Riau (UR) sebagai kampus hijau berbasis budaya Melayu adalah sebuah ide yang didukung sekaligus diperdebatkan di lingkungan kampus. Fenomena sosial ini menarik dikaji lebih dalam dengan tujuan menganalisis pontensi sosial-politik yang menopang green campus dan analisis ini pada akhirnya dimaksudkan untuk mengkomunikasikan berbagai sumberdaya yang ada untuk dapat dimobilisasi konteks penerapan kebijakan green campus.

Dewasa ini UR telah berusia setengah abad, dengan perjalanan yang cukup panjang tersebut, UR sebagai unit yang melahirkan banyak ilmuwan dan cendikiawan mampu menjadi universitas terdepan di Sumatera dan sekaligus menjadi lembaga pendidikan tinggi yang menjadi tulang punggung perkembangan kemajuan kebudayaan Melayu dalam memperkaya khasanah budaya nasional Indonesia. Harapan ini tentunya menjadi milik publik di Riau dan patut dipandang tidak berlebihan. Sejak bergulirnya reformasi sampai pasca otonomi Daerah dan derasnya pengaruh globalisasi, UR nampaknya berjuang keras menjadi kampus percontohan tingkat regional, nasional dan internasional yang mengedepankan tata kehidupan kampus dengan penerapan prinsip-prinsip pembangunan berkelanjutan (sustainable development) menuju Kampus Hijau (Green Campus) berbasis Budaya Melayu. Prinsip-prinsip pembangunan berkelanjutan telah dirumuskan oleh banyak pakar sejak KTT Bumi di Rio De Jeneiro Brazil 1990-an. Ada tiga pilar "Tripple P" yang saling terintegrasi antara Planet, Produksi dan Population. Masalahnya, bagi setiap Negara di dunia, adalah bagaimana menadopsi dan mengimplementasikan prinsip-prinsip pembangunan berkelanjutan tersebut dalam setiap Kebijakan, Rencana dan Program (KRP) pembangunan yang memenuhi kriteria kelestarian alam terjaga (Planet), memperoleh profit maksimal dari kegiatan ekonomi (Product) dan mampu mensejahterakan masyarakat kampus dan sekitarnya (Population) (Nirwago, 2013).

Sejalan dengan pandangan itu, Pemerintah Indonesia nampaknya berkomitmen betul untuk melaksanakan prinsip-prinsip pembangunan berkelanjutan dalam proses pembangunan. Salah satu kebijakan yang ditempuh adalah menyusun instrument pencegahan, pencemaran dan/atau kerusakan lingkungan hidup yang telah berada pada titik kritis dengan memberlakukan Undang-undang Nomor 32 Tahun 2009 Tentang Perlindungan dan Pengelolaan Lingkungan Hidup. Strategi pendekatan yang dilakukan adalah Penyusunan Kajian Lingkungan Hidup Strategis (KLHS) yang merupakan serangkaian analisis sistematis, menyeluruh dan partisipatif untuk memastikan bahwa prinsip-prinsip pembangunan berkelanjutan telah menjadi dasar dan terintegrasi dalam pembangunan suatu wilayah atau Kebijakan, Rencana dan Program (KRP) pembangunan. Beberapa indikator utama dalam menerapkan prinsip-prinsip pembangunan berkelanjutan yang menjadi sasaran KLHS yaitu: (1) Kapasitas 
daya dukung dan daya tampung lingkungann hidup untuk pembangunan; (2) Prakiraan mengenai dampak dan resiko lingkungan hidup; (3) Kinerja layanan/jasa ekosistem; (4) Efisiensi pemnfaatan sumberdaya alam; (5) Tingkat kerentanan dan kapasitas adaptasi terhadap perubahan iklim; (6) Tingkat ketahanan dan potensi keanekaragaman hayati; (7) Aspek sosial, ekonomi, dan budaya masyarakat yang selalu mengalami perubahan.

Selain pendekatan KLHS, Pemerintah Indonesia melalui Kementerian Kesehatan RI dalam Permenkes RI Nomor 2269/Menkes/PER/XI/2011 juga telah merumuskan "Pedoman Pembinaan Perialku Hidup Bersih dan Sehat (PHBS) yang harus diterapkan pada semua tatanan kehidupan, mulai dari tatanan keluarga/rumah tangga, tempat kerja, fasilitas umum, pelayanan kesehatan sampai di lingkungan institusi pendidikan dalam rangka mencapai Millennium Development Goals (MDGs) dengan mengimplementasikan 10 indikator PHBS, antara lain; mencuci tangan dengan sabun, mengkonsumsi makanan dan minuman yang bersih dan sehat, berolahraga secara teratur, mengunakan jamban sehat, membuang sampah di tempat sampah, tidak merokok, tidak mengkonsumsi narkotika, alcohol, psikotropika dan zat adiktif lainnya (NAPZA), tidak meludah sembarang tempat, memberantas jentik nyamuk dan sebagainya. (Permenkes No. 2268/Menkes/PER/XI/2011).

Jika dicermati secara seksama maksud dan manfaat KLHS dalam penyusunan Kebijakan, Rencana dan Program pembangunan (KRP) dan penerapan Program PHBS di lingungan institusi pendidikan, seperti Kampus Universitas Riau, ternyata kedua regulasi tersebut belum berjalan optimal sebagaimana yang diharapkan sesuai dengan prinsip-prinsip pembangunan berkelanjutan menuju Kampus Hijau (Green Campus) berbasis budaya Melayu. Secara factual hal ini terlihat dari misalnya sarana dan prasarana fisik kampus belum mencerminkan simbol budaya khas Melayu. Di sisi lain masih terlihat perilaku sivitas akademika kampus belum mencerminkan pola Hidup Bersih dan Sehat (PHBS), seperti tidak adanya regulasi tentang kawasan bebas rokok, kuruikulum program studi belum mendukung pengembangan potensi dan keanekaragaman lokal yang berwawasan Budaya Melayu. Dalam sejumlah fenomena sosial-politik seperti yang diuaraikan diatas inilah kajian ini dilaksanakan.

\section{KONSEP POLITIK EKOLOGI}

Tulisan ini disandarkan kepada konsep "Politik-Ekologi" dengan asumsi bahwa manusia dan lingkungan hidup merupakan suatu organisme kehidupan dalam kesatuan sistem yang saling berinteraksi, dalam system terdapat sub-sub sistem yang dapat berdiri sendiri dan membentuk system yang lebih luas. Argumen yang diketengahkan adalah pengelolaaan lingkungan green campus uiniversitas Riau merupakan wahana sosial untuk mengintegrasikan komunitas warga kampus dan luar kampus dalam konteks pembangunan berkelanjutan. Dalam kondisi seperti itu, ketegangan suatu sub-sistem atau tidak berfungsinya 
sub-sistem akan mempengaruhi berfungsinya sub-sistem lainnya. Setiap sistem memiliki tujuan (Goal) yang akan dicapai, untuk mencapai tujuan diperlukan pilihan-pilihan alat-alat atau strategi yang tepat. Kemudian, dalam menentukan alternative alat atau strategi untuk mencapai tujuan, sistem atau sub-sistem akan mempedomani standar normatif yang berlaku dan dibatasi oleh kondisi-kondisi situasional yang tersedia (Parsons, 1971).

Dalam konteks membangun kambus hijau, sangat diperlukan untuk merealisasikan konsep "politik ekologi". Para pakar lingkungan dikutip dalam Hidayat (2011) berpendapat bahwa "politik ekologi" adalah suatu pendekatan yang menggabungkan masalah lingkungan dengan politik ekonomi dan dinamika antara lingkungan dan manusia,dan antara kelompok bermacam-macam di dalam masyarakat dalam skala dari individu lokal kepada transnasional secara keseluruhan. Selanjutnya Blaiki dan Brookfield dalam Hidayat (2011) merangkum beberapa ilmuwan lain dalam mendefinisikan "politik ekologi" sebagai suatu bingkai untuk memahami kompleksitas saling hubungan antara masyarakat lokal, nasional, politik ekonomi global dan ekosistem. Selaras dengan cara pandang ini, konsep politik ekologi dapat diterapkan pada implementasi kebijakan kambus hijau,dimana semua pemangku kepentingan ke dalam universitas yang menjalankan kebijakan dan pilihan politik pembangunan ekonomi terkait pembagian wilayah kewenangan kelembagaan ke dalam universitas dalam hubungan kewenangan kelembagaan keluar misalnya Pemerintah Daerah atau Pemerintah Pusat. Dalam konteks pembahasan ini konsep politik ekologi menekankan peran stakeholder untuk berpartisipasi aktif dalam pengelolaan green campus yang berbasis budaya Melayu.

\section{METODE PENELITIAN}

Dalam rangka memahami kebutuhan analisis penelitian ini, langkahlangkah yang dilakukan adalah adalah: Pertama, identifikasi kondisi sosial-politik lingkungan kampus Universitas Riau, struktur sosial-politik, berbagai ketentuan yang menegatur lingkungan hidup yang diimplementasikan di UR. Sumber data skunder diperoleh dari bahan dokumen baik dicetak maupun elektronik. Sumber data skunder ini adalah laporan penelitian, jurnal ,buku-buku, peraturan perundangan baik berupa Undang-undang, Keputusan Menteri Peraturan Daerah yang Mengatur terkait lingkungan hidup, Surat Kabar Riau Pos, Peta Lokasi, Brosur, Selebaran, Risalah Rapat, Badan Pusat Stastistik ( BPS ), dan bahan yang bersumber dari websites in-ternet.

Selanjutnya, kedua, sumber data primer diperoleh dari hasil wawancara mendalam dengan para sifitas akademika UR. Tujuan wawancara itu adalah: pertama, untuk mmengungkapkan struktur sosial-politk masyarakat kampus UR; kedua, untuk mengumpulkan data mengenai kepentingan pimpinan, dosen, pegawai, mahasiswa, dan masyarakat sekitar kampus; dan Ketiga, untuk memperoleh pemahaman subjektifitas tineliti tentang bagaimana para sivitas akademika memandang interaksi dan pengorganisasian diri satu dengan lain. Sebelum memilih informan terlebih dahulu perlu menyusun peta sementara 
informan. Selain itu data kualitatif diperoleh dari observasi dan diskusi kelompok terarah (FGD). Untuk mengumpulkan data lebih lengkap informan dipilih berdasarkan posisi dan reputasi terkait kehidupan kampus,prinsipnya informan dipilih berdasarkan pengetahuan apakah aktor dapat memberikan informasi terkait implementasi program kampus hijau berbasis budaya Melayu.

\section{HASIL DAN PEMBAHASAN}

Dimensi sosial politik Pengelolaan Lingkungan Green Campus Universitas Riau Berbasis Konservasi dan Budaya Melayu dalam perspektif "politik ekologi" merupakan analisis deskriptif terhadap kondisi sosial politik di lingkungan masyarakat sekitar kampus Universitas Riau, di Kampus Bina Widya, Pekanbaru. Seperti yang sudah diuraikan terdahulu bahwa tujuan studi ini adalah mendeskripsikan potensi sosial-politik Kampus Hijau Binawidya Universitas Riau sebagai penopang sosial masyarakat. Tulisan menerapkan analisis kualitatif dengan menyajikan data deskriptif hasil observasi dan dokumentasi, data berdasarkan uraian verbal sesuai dengan hasil diskusi kelompok terfokus dan catatan lapangan menurut data hasil wawancara mendalam. Kemudian data diterjemahkan sesuai dengan kerangka prinsip-prinsip pembangunan berkelanjutan yang mengutamakan dimensi keseimbangan, keadilan dan keterkaitan Kebijakan. Kerangka hubungan konteks politik ekologi green campus dapat dilihat dari diagram pada Gambar 1.

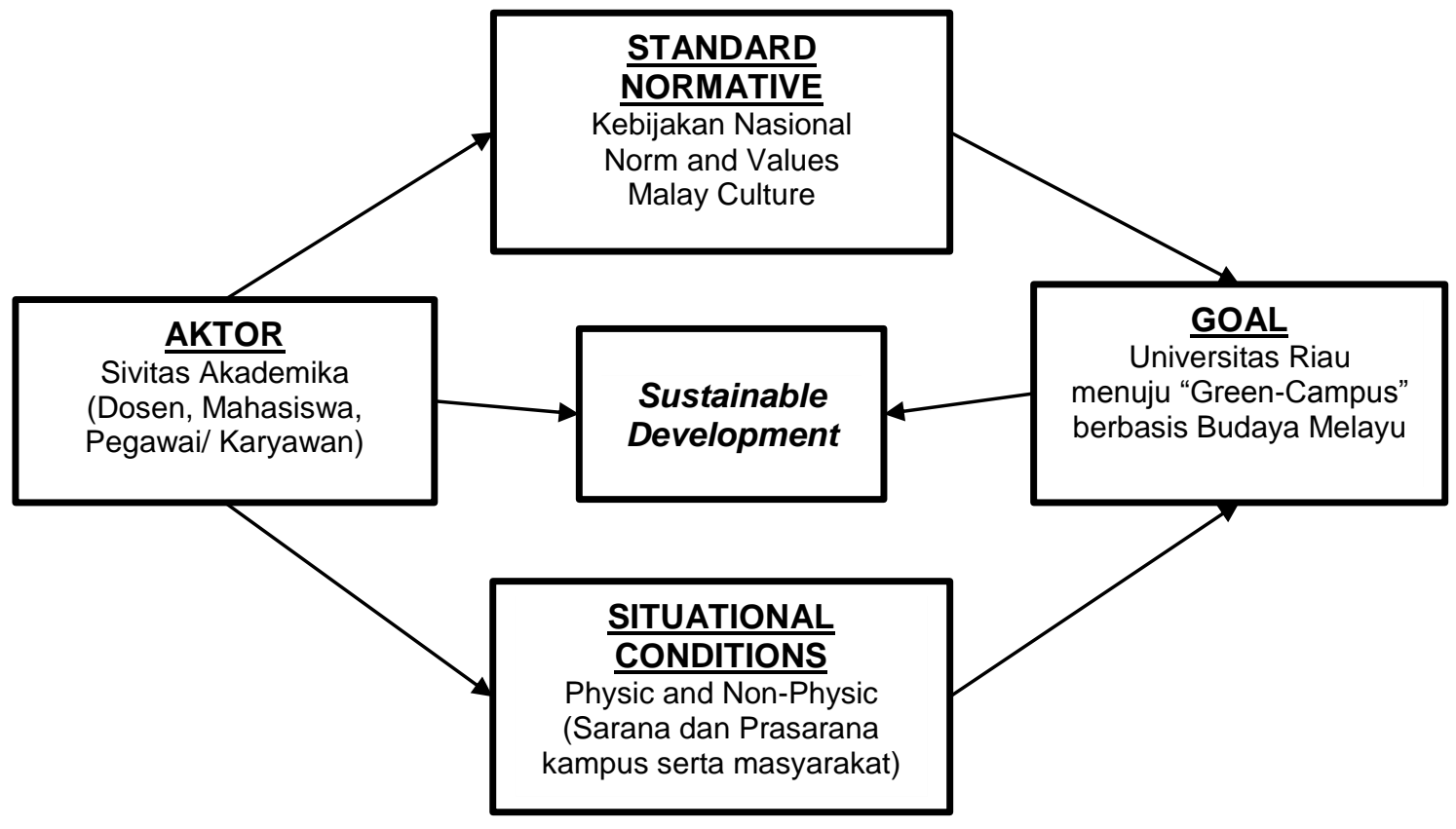

Sumber: Anwar dan Bahri, 2016

Gambar 1. Kerangka Hubungan Konteks Politik Ekologi Green Campus

Analisis yang bertumpu pada fenomena akibat adanya suatu pembangunan ataupun aktivitas kegiatan dalam konteks pengembangan kampus hijau berbasis budaya melayu. Analisis Kajian ini memiliki argumen bahwa 
pengelolaaan lingkungan green campus uiniversitas Riau berbasis konservasi dan budaya melayu merupakan wahana sosial untuk mengintegrasikan komunitas warga kampus dan luar kampus lebih harmonis. Kajian lingkungan sosial ini sedang berjalan dimulai dari bulan Juni 2016 hingga Oktober 2016. Proses identifikasi studi ini bertolak dari pembangunan waduk 1 dan 2 dengan sejumalah fakta lapangan adalah sebagai berikut: reaksi beberapa kelompok masyarakat kampus tentang skema kerja pengembangan waduk apakah kerja penelitian atau proyek pembangunan, beberapa kelompok ingin terlibat dalam proses kerja penelitian waduk secara fisik, dalam kondisi seperti itu memincu Ireaksi tim kajian untuk mengevaluasi rencana penelitian sesuai berbagai masukan dalam proses penelitian.

Implementasi kebijakan pencegahan, pencemaran dan/atau kerusakan lingkungan hidup selaras Undang-Undang Nomor 32 Tahun 2009 Tentang Perlindungan dan Pengelolaan Lingkungan Hidup dan prinsip-prinsip pembangunan berkelanjutan telah menjadi dasar dan terintegrasi dalam pembangunan suatu wilayah atau Kebijakan, Rencana, dan Program (KRP) pembangunan dan penerapan Program PHBS di lingungan institusi pendidikan, seperti Kampus Universitas Riau, ternyata kedua regulasi tersebut belum berjalan optimal sebagaimana yang diharapkan meskipun dalam perkembangannya menunjukkan hal yang mengembirakan ketika program kampus hijau mulai menggeliat kembali tahun 2016. Fenomena pembangunan berkelanjutan menuju Kampus Hijau (Green Campus) Berbasis Budaya Melayu dikatakan belumoptimal terlihat misalnya dari sarana dan prasarana fisik kampus seperti ornament/arsitektur gedung belum mencerminkan symbol budaya khas Melayu, area kampus masih sering dilanda bencana banjir tahunan, Ruang Terbuka Hijau (RTH) dan Pedestrian kampus belum tertata dengan baik dan menjadi prioritas program pembangunan universitas, sumberdaya air bersih utuk memenuhi kebutuhan warga kampus masih mengandalkan sumber air sumur bor dan tidak tersedianya kanal, waduk atau bendungan yang berfungsi sebagai resapan air bersih sekaligus menjadi upaya pencegahan banjir dan pengatur tata air yang keluar-masuk kampus dari berbagai sumber air dari sungai atau parit di sekitarnya (Anwar dan Bahri, 2016).

Di sisi lain masih terlihat pembangunan sarana laboratorium penunjang proses belajar-mengajar belum tertata sesuai dengan ketentuan standar Analisis Mengani Dampak Lingkungan (AMDAL) atau UKL/UPL. Begitu pula dengan perilaku sivitas akademika kampus belum mencerminkan PHBS, seperti tidak adanya regulasi tentang kawasan bebas rokok, penyediaan kawasan merokok, restorasi/kantin yang menyajikan makanan dan minuman yang memenuhi standar kesehatan, jarang dilakukan upaya penyemprotan jentik nyamuk, keluar masuknya kendaraan dan srana transportasi kampus kedalam ruang dan tempat berlangsungnya proses belajar mengajar dengan buangan emisi kendaraan yang tidak ramah lingkungan, tata ruang parkir kendaraan yang hiruk-pikuk dan sangat berdekatan sekali dengan ruang belajar, praktikum serta kegiatan akademik 
lainnya sehingga menganggu kenyamanan dan ketentraman sivitas akademika (Anwar dan Bahri, 2016).

Selain itu, dari aspek kurikulum pendidikan tinggi yang mengarah pada Pola Ilmiah Pokok (PIP) Universitas Riau ternyata masih banyak program studi dan keahlian yang tersedia di Kampus Universitas Riau belum sepenuhnya mendukung pengembangan potensi dan keanekaragaman lokal yang berwawasan Budaya Melayu, antara lain program studi atau fakultas IImu Budaya (seni sastra, seni music, seni rupa), Antropologi Fisik/Arkeologi, Perkebunan, Perikanan dan Pertanian yang bersifat "Eco-green" sesuai dengan potensi sumberdaya alam daerah, Teknik Lingkungan, Ekonomi Lingkungan, Pendidikan Lingkungan, Politik Lingkungan, Sosiologi Lingkungan, dan sebagainya. Begitu juga dengan belum adanya kawasan taman pendidikan yang dapat dimanfaatkan untuk berbagai fungsi, seperti penelitian, paru-paru kampus, taman eco-wisata, pecinta alam dan berbagai kepentingan akademik sivitas akademika. Bertolak dari sejumlah fenomena tersebut, maka perlu kiranya dilakukan riset Rencana dan Program Kampus Universitas Riau Menuju Kampus Hijau (Green Campus) Berbasis Budaya Melayu (Anwar dan Bahri, 2016).

Seperti yang diungkapkan diatas bahwa analisis riset diarahkan kepada upaya mendapatkan pemahaman awal terkait konteks sosial-politik penopang desain pengelolaan lingkungan green campus berbasis budaya melayu di universitas Riau. Dalam rangka mencapai tujuan tata kelola kampus hijau maka analisis riset ini akan diarahkan kepada tiga konsep dasar penelitian,yaitu aktor kampus, regulasi,dan sarana dan prasarana kampus.

\section{Para Aktor}

Dewasa ini UR sedang bergerak ke arah pembangunan (dalam hal ini) green campus berbasis budaya Melayu dengan tujuan untuk memberikan model kepada masyarakat dan kampus lainnya (Green Indonesia, 2016). Hal ini selaras dengan visi UR adalah universitas riset yang cemerlang berbasis pengembangan sumber daya kawasan perairan dan budaya melayu tahun 2035 Untuk mewujudkannya UR sudah mempersiapkan sedemikian rupa misalnya terus menerus meningkatkan kualitas dan jumlah tenaga pengajar (dosen) yang berkualifikasi sebanyak 1.057 orang dengan rincian sebagai berikut: Guru besar/professor 53 orang; Lektor kepala 406 orang; Lektor 333 orang dan asisten ahli 205 orang (Profil Universitas Riau, 2016). Secara rinci menurut Fakultas dapat dilihat pada Tabel 1.

Tabel 1. Jumlah Dosen Universitas Riau Tahun 2016

\begin{tabular}{|c|c|c|}
\hline No & Fakultas & Jumlah \\
\hline 1. & FISIP & 100 orang \\
\hline 2. & Fakultas Ekonomi & 128 orang \\
\hline 3. & FMIPA & 125 orang \\
\hline 4. & Faperika & 107 orang \\
\hline 5. & FKIP & 210 orang \\
\hline 6. & Fakultas Pertanian & 96 orang \\
\hline
\end{tabular}




\begin{tabular}{|c|c|c|}
\hline No & Fakultas & Jumlah \\
\hline 7. & FakultasTeknik & 156 orang \\
\hline 8. & Fakultas Kedokteran & 73 orang \\
\hline 9. & Fakultas Hukum & 30 orang \\
\hline
\end{tabular}

Sumber: Profil UR dalam Anwar dan Bahri, 2016

UR dalam perkembangannya memiliki para dosen dengan jenjang pendidikannya terus meningkat S1 sebanyak 81 orang, S2 sebanyak 682 orang, S3 berjumlah 276 orang, spesialis 1 berjumlah 17 orang, dan spesialis 1 orang. Berbagai sumberdaya manusia ini akan menjadi penopang utama bagaimana tata kelola green campus di UR akan diformulasikan, implementasi dan dievaluasi dalam rangka mencapai tujuan untuk mengintegrasikan komunitas kampus dan masyarakat sekitarnya.

Sejalan dengan hal diatas dalam rangka menopang struktur sosial kebijakan kampus hijau, UR memiliki beberapa lembaga internal sesuai dengan organ dan susunan organisasi organ UR. Organ ini selaras dengan Undangundang Nomor 20 Tahun 2003 tentang Sistem Pendidikan Nasional dan peraturan pelaksanaannya. Organ tersebut adalah Rektor, Wakil Rektor, Senat UR, Satuan Pengawas, Dewan Pertimbangan, dan organ lainnya. Beberapa organ ini dimaksudkan sebagai struktur penopang desain system kinerja lembaga ke depan tentu termasuk pelembagaan tata kelola kampus hijau berbasis konservasi dan budaya melayu. Berbagai organ tersebut misalnya rector dan wakil rector sebagai unsure pimpinan rektorat, senat Universitas yang mempresentasikan civitas akademika kampus. Lembaga ini terdiri dari para guru besar, wakil dosen, wakil pegawai, dan wakil mahasiswa. Sementara itu, UR memiliki Satuan Pengawas Internal yang bersifat independen melaksanakan pengawasan dalam pelaksanaan kegiatan Universitas di bidang non-akademik. Dewan Pertimbangan memberi pertimbangan otonomi UR bidang non-akademik dan fungsi lainnya. Dewan ini beranggotakan tokoh-tokoh masyarakat, alumni, dan pakar pendidikan.

Selain itu, UR memiliki unsur Pelaksana Administrasi, Unsur Pengembangan dan Pelaksana Tugas Strategis, Unsur Pelaksana Akademik, dan unsur lainnya. Secara kelembagaan unsur tersebut terdiri dari Badan Pengembangan Layanan Teknis (BPLT), Badan Pengembangan Usaha (BPU) yang terdiri dari Unit Pengelola Usaha (UPU) yaitu Layanan kesehatan (Rumah Sakit), UPU Pengembangan Karisr dan Kewirausahaan,UPU UR Press.Selanjutnya Ur memiliki Lembaga Penelitian dan Kepada sPengabdian Masyarakat (LPPM).Lembaga ini memiliki sejumalh pusat studi sebagai unit pengembangan riset dan pengabdian kepada masyarakat. Pusat-pusat studi itu adalah: Pusat Studi Kawasan Pantai dan Perairan (PSKPP), Pusat Studi Budaya Melayu (PSBM), Pusat Studi Lingkungan Hidup (PSLH), Pusat Studi Sosial Ekonomi (PSSE), Pusat Studi Industri dan Perkotaan (PSIP), Pusat Studi Kependudukan dan Peranan Wanita (PSKPW), Pusat Studi Pangan, Energi dan Bioteknologi (PSPEB), Pusat Studi Perkebunan, Gambut dan Pedesaan (PSPGP), Pusat Penelitian Hak Asasi Manusia (PPHam), Pusat HAKI, Promosi 
dan Pengembangan IPTEK, Pusat Studi Kesehatan, Pusat Studi Bencana (PSB), Pusat Pengembangan Kukerta (PPK),dan Pusat Studi Masyarakat Ekonomi Asean. Selain mahsiawa terdapat alumni berjumlah 6.352 orang. Sementara itu, UR memiliki 50 laboratorium yang tersebar di fakultas-fakultas.

Upaya identifikasi struktur sosial yang mendukung desain lingkungan green campus sudah barang tentu terkait dengan unsur komunitas mahasiswa yang tersebar berbagai fakultas dan jurusan baik di tingkatan Strata 1 (S1), Strata 2 (S2) dan Strata 3 (S3). Sebagai peserta didik yang telah memenuhi syarat, terdaftar dan belajar di UR, mahasiswa mempunyai peranan yang sangat strategis dalam kehidupan kampus. Setelah selesaipun para mahasiwa yang disebut Alumni tetatap memiliki peran strategis sebagai struktur pendukung keberlanjutan implemantasi desain kehidupan kampus yang berbasis konservasi dan budaya melayu.

Komponen mahasiswa pad akhirnya adalah elemen pembuat dan sekaligus pengguna produk gereen kampus berkelanjutan. Dalam perkembangannya jumlah mahasiswa terus bertambah tiap tahun sejalan dengan penambahan fakultas dan jurusan yang ada di UR. Dalam tahun 2016, jumlah mahasiswa UR sebanyak 33.558 orang secara rinci dapat dilihat Tabel 2.

Tabel 2. Jumlah Mahasiswa UR tahun 2016

\begin{tabular}{|c|c|c|}
\hline No & Fakultas & Jumlah \\
\hline 1. & FISIP & 5.515 orang \\
\hline 2. & Fakultas Ekonomi & 6.609 orang \\
\hline 3. & FMIPA & 2.401 orang \\
\hline 4. & Faperika & 2.864 orang \\
\hline 5. & FKIP & 5.567 orang \\
\hline 6. & Fakultas Pertanian & 2.395 orang \\
\hline 7. & Fakultas Teknik & 3.203 orang \\
\hline 8. & Fakultas Kedokteran & 868 orang \\
\hline 9. & Fakultas Hukum & 1.612 orang \\
\hline 10. & Pascasarjana & 1.978 orang \\
\hline
\end{tabular}

Kehadiran sekolah Pascasarjana tahun 2002 telah memberikan percepatan tersendiri terutama dalam konteks mewujudkan UR sebagai universitas riset. Sekolah Pascasarjana adalah penyelenggara pascasarjana yang ada di UR, yaitu unsur pelaksana akademik pada universitas yang meliputi program Magister dan Doktor. Berbasiskan pola IImiah Pokok (PIP) UR, yaitu yang mengarah kepada kebijakan dan strategi pengembangan sebagai manifestasi dalam seluruh aktivitas pengembangan ilmu pengetahuan, teknologi, seni dan atau olahraga. Kondisi ini diharapkan menjadi unggulan dan karakteristik pembeda antara desain kampus hijau UR dengan perguruan tinggi lainnya di Indonesia. Untuk itu, dibutuhakan identifikasi terhadap potensi sosial dan budaya komunitas civitas akademika UR dan masyarakat sekitarnya dalam rangka upaya memulai memahami aspirasi dan harapan dengan tujuan menyiapkan warga kampus dan masyarakat untuk berpartisipasi dalam 
mendukung desain tata kelola kampus hijau. Adapun beberapa aspirasi dan harapan tersebut adalah:

\section{Keamanan dan kebersihan kampus}

Dalam riset ini ditemukan bahwa konsep green campus berkelanjutan memang tidak dapat dipisahkan dengan unsur keamanan dan kebersihan kampus. Rasa aman dan kondisi bersih menjadi harapan pokok bagi civitas dan masyarakat sekitar kampus. Hal ini terlihat dari harapan informan. Menurut informan bahwa kampus hijau dimengerti pada dasarnya sebagai taman kampus. Ide ini disenangi masyarakat untuk bembawa keluarganya, belajar, bermain, dan beristirahat. Hanya saja kebersihan dan keamanan taman yang penting diperhatikan. Taman ini bermanfaat bagi kami sekeluarga tempat melepas lelah setelah berkerja sehari-hari di depan komputer. Demikian pula informan lainnya, berharap kampus memiliki udara segar, lahan hijaunya luas, tenang rasanya hati ini. Pengembangan kampus hijau sangat baik karena membuat pengunjung kampus terutama mahasiswa nyaman. Kampus menjadi bersih dan aman, untuk itu bukan hanya waduk tetapi juga pohon (sebagai paru-paru dunia) kalau waduk kesannya terjadi erosi (kering kerontang, pohan yang ada ditebang, butuh waktu menanam kembali). Selain itu, keamanan kampus diperkuat karena jangan terjadi tempat perilaku menyimpang teruma malam hari (pacaran). Informan lainnya dari unsur masyasrakat berpendapat sama bahwa jangan salah menggunakannya, misalnya pada malam hari sebagai tempat muda mudi berpacaran. Sejalan dengan informan sebelumnya, mahasiswa berpendapat sama komponen komunitas kampus adalah yang utama dalam menjaga kebersihan dan keamanan. Green campus adalah kampus rindang, waduk dengan pohon yang rindang. Pohon-pohon sudah ada tinggal merawatnya. Keamanan harus kuat (informan pegawai). Selain itu kenyamanan, keamanan, dan ketrsediaan tenaga kebersihan. Kami (informan ESU) bekerja setiap hari liburnya hanya pada tanggal merah. Orang yang masuk ke taman dalam kampus melihat waduk misalnya harus aman misalnya mendapat akses dari kartu atau tiket. Sebab dulu sering terjadi pencurian (informan petugas). Agar kampus udara segar dan dingin, karena dulu bangunan tidak memakai AC karena banyak pohon. Patroli sering dilakukan terutama pada malam hari (informan pegawai).

\section{Struktur kelembagaan}

Secara struktural, posisi unit rumah tangga di UR memegang peran penting. Karena unit inilah sesuai tupoksinya yang berwenang mengelola kebersihan kampus. Dalam perkembangannya hadir ESU yang dipersepsikan mampu membantu unit rumah tangga misalnya jika ada pohon yang tumbang, jalan yang berlobang agar cepat ditangani. ESU lembaga non-structural yang bertanggungjawab langsung kepada Rektor. Jadi intinya unit rumah tangga rektorat sesuai SOTK baru 2014 harus kuat dan didukung oleh angggaran yang memadai.

\section{Efisiensi dan kinerja}


Tata kelola lingkungan kampus hijau membutuhkan dukungan personil petugas kebersihan dan sarana yang cukup. Menurut informan bahwa jumlah petugas dibandingkan dengan luas wilayah kerja kebersihan kurang seimbang. Sementara itu, sarana tempat sampah belum memadai. Pengangkutan sampah dari berbagai lokasi di kampus untuk dibuang ke TPA sampah kampus. Piringan dan penyiangan tanaman bunga. Potong rumput, pemeliharaan kebersihan gedung dan halaman. Lain halnya informan lainnya bahwa pemeliharaan jembatan pedestrian dan fasilitas taman dan kajian melalui pembangunan waduk begitu mahal. Gagasan ini sudah lama dibicarakan, namun saya menolaknya karena lebih baik membangun kawasan taman di sekitar pintu masuk belakang kampus. Sementara itu, informan berikutnya berpendapat lain bahwa waduk yang dibangun ini bermanfaat untuk tempat baik untuk memancing selain menambah keindahan kampus.

Berikut berbagai peraturan perundangan yang terkait:

- UU No.5/1990 Tentang Konservasi dan Sumberdaya Alam Hayati.

- UU No.5/1992 Tentang Benda Cagar Budaya.

- UU No.28/2002 Tentang Bangunan Gedung.

- UU No.7/2004 Tentang Sumberdaya Air.

- UU No.18/2004 Tentang Perkebunan.

- UU No.25/2004 Tentang Sistem Perencanaan Pembangunan Nasional.

- UU. No. 32/2004 Tentang Pemerintahan Daerah.

- UU No.38/2004 Tantang Jalan.

- UU No. 24/2007 Tenatng Penanggulangan Bencana.

- UU No.26/2007 Tentang Penataan Ruang.

- UU No.18/2008 Tentang Pengelolaan Sampaj.

- UU No.10/2009 Tentang Kepariwisataan.

- UU No.22/2009 Tentang LLAJ.

- UU No.32/2009 Tentang Perlindungan dan Pengelolaan Lingkungan Hidup.

- UU No.1/2011 tentang Perumahan dan Kawasan Permukiman.

- PP No.16/2009 Tentang Penatagunaan Tanah.

- PP No.26/2008 Tentang RTRW Nasional.

- PP No.43/2008 Tentang Air Tanah.

- PP No.24/2009 Tentang Kawasan Industri.

- PP No.68/2010 Tentang Peranserta Masyarakat Dalam Penataan Ruang

- Keppres No.57/1980 Tentang Pengelolaan Kawasan Budidaya.

- Keppres No.32/1990 Tentang Pengelolaan Kawasan Lindung.

- Permen KLH No17/2009 Tentang Pedoman Penataan Daya Dukung Dalam Penataan Ruang.

- Permen KLH No 27/2009 Tentang Pedoman pelaksanaan KLHS.

- Permen KLH No.09/2011 tentang Pedoman Umum KLHS.

\section{Sarana dan Prasarana}

Dewasa ini Universitas Riau sudah memiliki sarana dan prasarana penunjang pengembangan kampus hijau meskipun dalam banyak hal belum 
memadai. Adapun Sarana dan prasarana di kampus Universitas Riau berupa gerai/kantin (22 unit); mushalla (7 unit); gelanggang mahasiswa (1 unit); lapangan parkir (14 unit); tempat sampah; bangunan halte/shelter (5 buah); tempat duduk taman; truk Sampah (1 unit); taman permanen (7 unit); waduk (2 buah); micro bus ber penumpang 25-29 orang (5 unit); bus (kapasitas lebih dari 30 orang, 1 unit); mobil ambulans (1 unit); kapal penangkap ikan, 1 unit); mobil tanki air (1 unit); golf car (1 unit); gedung pos jaga (7 unit); pondopo; rang jembatan kupu-kupu; jembatan batu penghubung; dan, trotoar pejalan kaki.

\section{PENUTUP}

Pada bagian penutup ini penulis ingin membuat pernyataan bahwa gerakan pengelolaan desain green campus berbasis budaya Melayu adalah tindakan kolektif bukan individual. Karena itu persoalaan implementasi bukanlah persoalan teknis administratif melainkan kompleks terkait berbagai dimensi misalnya sosial, ekonomi, budaya, dan teknologi di luar dan dalam kampus. Gerakan UR dalam mendesain kampus hijau adalah kreativitas bersama dalam pembangunan berkelanjutan, lembaga ini melalui gerakan lingkungan green campus menyebarkan pengetahuan inovasi, teknologi, dan efisiensi energi ke depan bagi semua. Upaya bersama ini akan berjalan baik jika didukung oleh partisipasi warga kampus, masyarakat, dan pemerintah. Untuk itu, komunikasi sosial pengelolaan konflik dan pengakuan akan hak masing-masing adalah pintu masuk pembangunan green kampus berkelanjutan. Kami berharap, riset awal ini menjadi inspirasi dalam melakukan penelitian-penelitian selanjutnya, terima kasih kepada Pusat Studi Lingkungan Hidup dan LPPM Universitas Riau.

\section{DAFTAR PUSTAKA}

Anwar, K. dan S. Bahri. 2016. Identifikasi dan Inventarisasi beberapa Potensi Sosial Budaya Desain Pengelolaan Green Campus Universitas Riau dalam Laporan Penelitian Pengelolaan Kampus Hijau Berbasis Konservasi dan Budaya Melayu, PSLH Universitas Riau. Pekanbaru: Unri Press.

Green Indonesia. 2016. Implementasi Konsep Green Campus. Majalah Bisnis \& Kelestarian Lingkungan. Nomor 3/tahun II/2016.

Hidayat, H. 2011. Politik Ekologi, Pengelolaan Taman Nasional Era Otda. Jakarta: LIPI Press.

Nirwago, J. 2013. Kota Hijau (Green-City). Jakarta: Gramedia.

Parsons, T. 1971. The Social System. London: Routledge and Kegan Paul.

Peraturan Menteri Kesehatan Republik Indonesia, No. 2268/Menkes/PER/XI/2011 tentang Pedoman Pelaksanaan Pola Hidup Bersih dan Sehat (PHBS). Jakarta: Kementerian Kesehatan RI.

Peraturan Menteri Lingkungan Hidup Republik Indonesia, Nomor 27 tahun 2009 tentang Pedoman Pelaksanaan Kajian Lingkungan Hidup Strategis (KLHS). Jakarta: Kementerian Lingkungan Hidup. 
Universitas Riau. 2016. Profil Universitas Riau 2015. Pekanbaru: Unri Press. 